In Memoriam

\title{
Dr. John Viner Lloyd, MBBS, MD, PhD, FRACP, OAM (1939-2012)
}

\author{
Susan Rodgers, BSc, MAppSc ${ }^{1}$ \\ ${ }^{1}$ Haemostasis Laboratory, Institute of Medical and Veterinary Science \\ (IMVS), South Australia, Australia
}

Semin Thromb Hemost 2013;39:233-234.

John Lloyd was a much-respected hematologist who was an expert in the field of thrombosis and hemostasis, particularly in the area of hemophilia care. He was director of the Adult Haemophilia Center in Adelaide for over 30 years and was a key member of the Australian Haemophilia Centre Directors Organization (AHCDO), which advocates for better treatment options for patients with bleeding disorders. In the 2012 Queen's Birthday Honors, John was awarded the Order of Australia Medal in the General Division, in recognition of his services to medicine in the field of hematology, to medical education, and to professional organizations. John was always well liked and respected by his patients, staff of the Institute of Medical and Veterinary Science (IMVS), and other institutions. He was an integral part of the expansion of knowledge and treatment of hemophilia and other bleeding disorders in South Australia.

John was born in Adelaide, South Australia, and educated at Prince Alfred College where he excelled, receiving many academic prizes, and scholarships. After graduating from medicine with an MBBS in 1964 from the University of Adelaide, he completed an MD on "Platelets and ascorbic acid" in the Department of Medicine. This was followed by a PhD between 1968 and 1972 on "Phosphatidic acid and phosphoinositides in platelets" at the McMaster University in Canada, which led to new concepts of the role of phospholipids in platelet membranes. He returned to Australia to further his interest in clinical hematological disorders, and gained his fellowship of the Royal Australian College of Physicians before joining the Haematology Division of the IMVS in Adelaide as a consultant in 1975. He was appointed as the hematologist in charge of the hemostasis and thrombosis laboratory, and also took primary responsibility for the care of all patients with disorders of hemostasis or thrombosis at the IMVS and Royal Adelaide Hospital (RAH). From 1987 to 1996, he was also director of transfusion medicine.

One of his main interests when he started at the IMVS was in platelet function, and the old single channel platelet aggregometer in the laboratory was soon replaced by two

dual channel aggregometers. He and his laboratory investigated the effect of storage conditions of plateletrich plasma on platelet aggregation

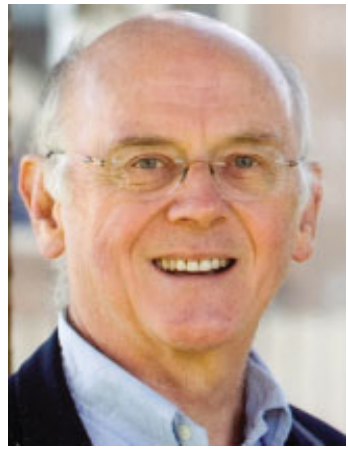

Dr. John Viner Lloyd studies, resulting in several publications. The results of this work were also presented at the annual conferences of the Australian Society for Medical Research, the main forum for hemostasis science at that time. John was the organizer of the Thrombosis Haemostasis Discussion Group of Australia, which met at these conferences, and this group was instrumental in transferring the forum for hemostasis and thrombosis to the annual conference of the Haematology Society of Australia and New Zealand.

Some years later, John developed a collaborative relationship with Professor Felix Bochner of the Department of Clinical and Experimental Pharmacology of the University of Adelaide. This was a fruitful cross-departmental association: the Pharmacology Department provided pharmacokinetic expertise and various honors students, and the hemostasis laboratory supervised these students in platelet aggregation studies. The effect of various formulations and doses of aspirin on platelet aggregation were studied, as well as other antiplatelet agents, such as dipyridamole, also resulting in several articles.

Throughout this time, John was also busy with his clinical duties of caring for patients with bleeding and clotting disorders, as well as thalassemia; earning the respect and appreciation from these patients; and becoming involved in the local hemophilia and thalassemia societies. For several years, he was almost wholly responsible for the management of these patients, with other hematologists from the department stepping in when he was away. He was also a founding member of the national Haemophilia Medical Advisory Panel, which later became the AHCDO. This group provides advice to the government, and also advocates for access to better treatment products for patients with hemophilia and other bleeding disorders, culminating recently in the availability of

Copyright ( $) 2013$ by Thieme Medical Publishers, Inc., 333 Seventh Avenue, New York, NY 10001, USA. Tel: +1(212) 584-4662.
DOI http://dx.doi.org/ 10.1055/s-0033-1334465. ISSN 0094-6176.

Haemostasis Laboratory, Institute

of Medical and Veterinary Science 
recombinant products for all hemophilia patients. He was awarded the prestigious Ron Sawers Award by the Haemophilia Foundation of Australia in 2007, in recognition of his care and commitment to the clinical needs and welfare of people with hemophilia and related bleeding disorders as well as his research work, by then spanning over four decades. In 2003, he was awarded the CSL Peter Schiff award by the Australian and New Zealand Society of Blood Transfusion, for his contribution to transfusion medicine and hemophilia treatment.

John was also Clinical Associate Professor, Faculty of Health Sciences at the University of Adelaide, and was very involved in the teaching of both preclinical and clinical medicine to medical students and young doctors. He supervised many postgraduate students and also examined many theses. He was always willing to mentor others and share his extensive medical knowledge and experience with colleagues and students alike.

John was always very supportive of the scientists in the hemostasis laboratory, which expanded considerably during his time at the IMVS. Improvement of tests for detection of hemophilia carriers was one area of interest, which was later useful in a joint project with the Human Genetics Department at the Women's and Children's Hospital, to determine the spontaneous mutation rate for hemophilia A. A nurse was employed to document the family trees of all hemophilia patients born in South Australia, to determine those with no known family history, and to assess the probability of carrier status of all females from these families. Subsequent hemophilia research, in association with Elizabeth Duncan, focused on a subgroup of mild hemophilia patients, from a small number of families, in whom there was a considerable discrepancy between one-stage and two-stage factor VIII assays. This work included mutation analysis of these pa- tients, in collaboration with Dr. Zbigniew Rudzki from the Molecular Pathology Division, which eventually resulted in world-wide recognition of this hemophilia subgroup, and which led to the modification of an automated chromogenic assay for diagnosis of these patients. Deoxyribonucleic acid analysis was continued to determine the mutation in all hemophilia patients in South Australia, which has provided a much improved carrier diagnosis for all females in these families, as well as diagnosis of babies at birth. The earlier work in documenting the family history of all patients made mutation analysis much faster and more economical, as the causative mutation was already known for many families.

During his career, he was awarded more than 30 research grants, mainly concerned with hemophilia and platelet function, with findings published in esteemed international medical journals and presented at conferences throughout the world. He was a member of more than 30 committees spanning local, Australian and international committees, including those relating to the IMVS/RAH, hemophilia, thalassemia, transfusion, and the University of Adelaide.

Outside work, John had many personal interests, which included a love of choral and opera music, history, and nature -especially Australian native plants. He was a keen tennis, golf, and bridge player, activities that involved his many friends and colleagues. As an example, he held tennis afternoons at his family home for his wide circle of friends for more than 30 years, only stopping in the last few weeks of his illness. During his long battle with cancer, John continued to be actively involved in his professional and personal interests. He followed the many activities of his children and six grandchildren, with great interest. He had a courageous and positive outlook throughout his illness.

He will be deeply missed by his family, friends, and colleagues. 